\title{
Thoraco-omphalopagus twins: different perinatal circumstances, different outcome
}

Anna Piaseczna-Piotrowska ${ }^{1}$, Andrzej Chilarski ${ }^{1}$, Wojciech Krajewski ${ }^{2}$, Joanna Godlewska-Tarka

${ }^{1}$ Department of Paediatric Surgery and Urology, Polish Mother's Health Centre Institute, Medical University of Lodz, Lodz, Poland

2Department of Anaesthesiology and Intensive Care, Polish Mother's Health Centre Institute, Medical University of Lodz, Lodz, Poland

Submitted: 16 March 2009

Accepted: 26 May 2009

Arch Med Sci 2010; 6, 3: 461-463

DOI: 10.5114/aoms.2010.14272

Copyright $\odot 2010$ Termedia \& Banach

\section{Abstract}

Two pairs of omphalopagus twins were encountered at the Polish Mother's Health Institution in Lodz, Poland during the past 15 years. In the first set the prenatal diagnosis was not established and the delivery of the twins in a regional hospital was a complete surprise. Both babies died. In the second case the conjoined twins were diagnosed prenatally, surgical separation was successful, and both twins survived. The prenatal identification of conjoined twins is of cardinal importance for the planning of delivery and possible separation.

Key words: conjoined twins, prenatal diagnosis, surgical separation.

\section{Introduction}

The incidence of conjoined twins is approximately 1 in 50000 to 200 000 births. The majority are stillborn or die soon after birth [1-3]. The prenatal identification of conjoined twins is of cardinal importance for the planning of delivery and possible separation [4-7]. This is a retrospective review of the management of two pairs of female omphalopagus twins at the Polish Mother's Health Institution in Lodz, Poland during the past 15 years.

\section{Case reports}

\section{First set}

Conjoined female twins were born in a regional hospital at 38 weeks' gestation by caesarean section. It was a complete surprise for the obstetricians as no prenatal USG was performed and no prenatal diagnosis was established. Delivery took place at 8.30 a.m. and the twins reached the NICU in our institution at 1 p.m.

The twins were connected by an extensively large omphalocele. The amniotic membrane was torn and only remnants of it were possible to identify. The common liver was fully exposed and the bowels were eviscerated.

Twin A was in a very grave condition, conscious, reactive but hypotensive and hypothermic. The infant was intubated and pharmacotherapy (dopamine) was instituted. Twin B on admission was in a critical condition:
Corresponding author: Anna Piaseczna-Piotrowska Department of Paediatric Surgery and Urology Polish Mother's Health Centre Institute Medical University of Lodz

Rzgowska 281/289

93-338 Lodz, Poland Phone: 0048422712136 Fax: 0048422711358 E-mail: annapiaseczna@yahoo.com 
unconscious, flaccid, already previously intubated and ventilated. Pulse was non-palpable and heart rate was $60 / \mathrm{min}$. Indirect heart massage was ineffective.

The twins were transferred to the operating theatre and an attempt of emergency separation was undertaken. Evaluation on the operating table revealed that they shared the bridge of a common liver but they had separate portal veins, hepatic arteries and bile ducts together with gallbladders. There was a double duodenum with Vater's ampulla and the duodenum of twin B ended in that of twin A, well behind Vater's ampulla. The twins shared a common jejunum that ended in a common giant reservoir. The ileum and large bowels were separated. It turned out that the bile ducts and gallbladder of twin B were atretic. Separation of the liver was the first step of the procedure and it was completed smoothly. The continuous resuscitation of twin B was ineffective and the infant was considered dead. Integration of the alimentary tract was completed easily and jejuno-ileal anastomosis was constructed in twin A but the second child died too at the end of the operation.

\section{Second set}

Symmetrical thoraco-omphalopagus female conjoined twins were born in our institution by elective caesarean section at 34 weeks' gestation with a combined weight of $4.2 \mathrm{~kg}$. At 5' Apgar scores were respectively: 8 (twin A) and 7 (twin B). Prenatal diagnosis by ultrasound was established at 26 weeks' gestation.

The infants were joined face-to-face from the xiphoid to the umbilicus (Figure 1). There was a single umbilical cord. The ultrasound Doppler examination and computed tomography (Figure 2) showed:

- two separated hearts that shared a portion of pericardium; both hearts had a small ventricular septal defect (VSD) and a patent ductus arteriosus;

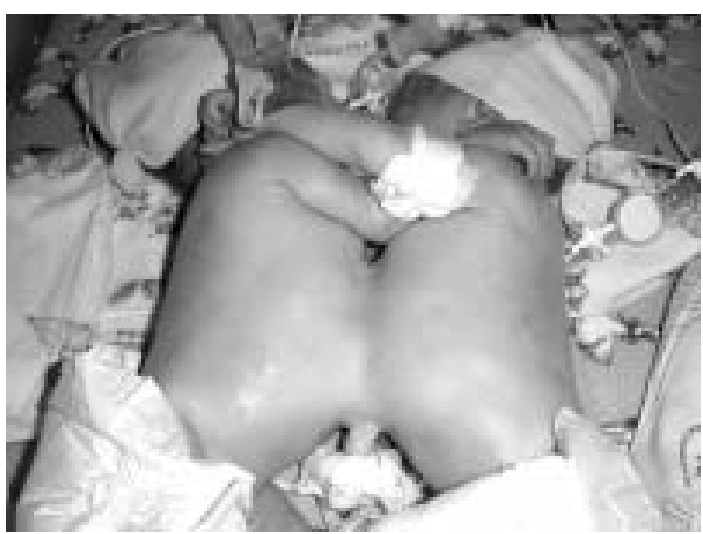

Figure 1. Conjoined twins (set 2) on the second day of their life
- a fused liver with two separate extrahepatic biliary systems and two separated blood supply systems; - the upper and lower gastrointestinal tracts were separated;

- each twin had two normal appearing kidneys and a urinary bladder.

Surgical correction of the twins was performed at the end of the $3^{\text {rd }}$ month of life. Separation started with longitudinal division of the abdominal layers. Then the liver was split with argon beam electrocautery to minimize blood loss. During the separation of the xiphoid and costal connection the shared portions of pericardium and diaphragm were divided and sutured. The abdominal wall defect was closed without prosthetic material. The postoperative course in both babies was satisfactory. Both twins were ventilated for 3 (twin A) or 2 (twin B) days. During the first days after the operation moderate tension of the abdominal parietes was observed. Enteral feeding was commenced and increased to full volume by the $4^{\text {th }}$ day postoperatively. On day 22 the babies were discharged home. The girls are under regular medical care. They are healthy and thriving.

\section{Discussion}

The overall mortality rate in conjoined twins is believed to be about $85 \%$. The exact figures are

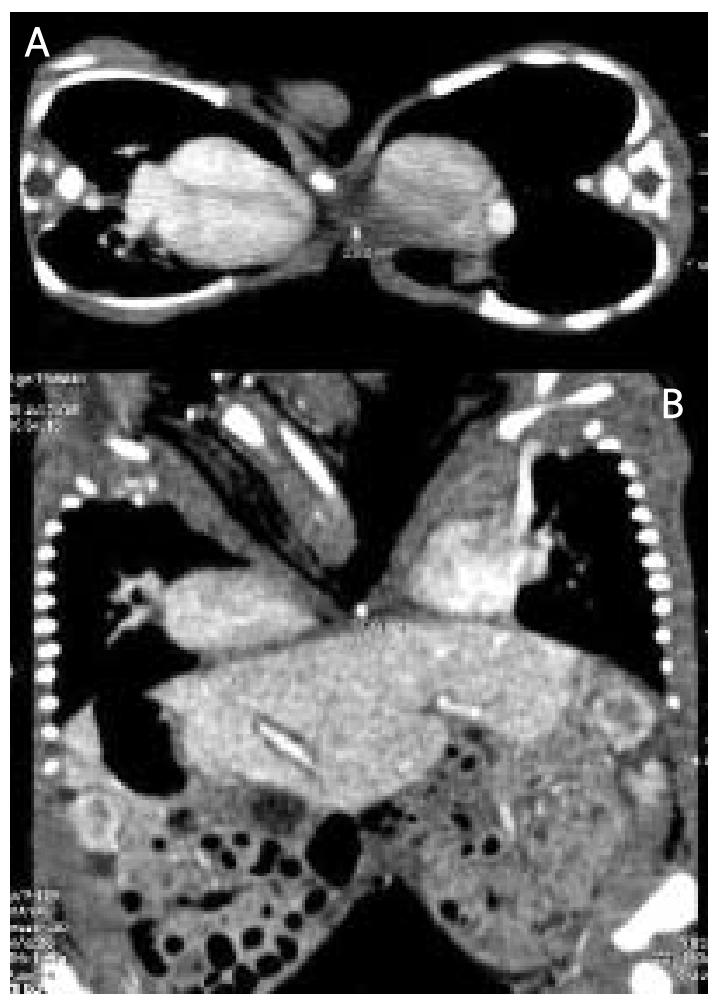

Figure 2. CT scans (set 2): A - transverse section. Twins were conjoined between the xiphoid process; $\mathrm{B}$ - oblique-coronal reconstruction. Left hepatic lobes fusion 
difficult to establish because of the high incidence of death in utero $( \pm 30 \%)$ and possible options for termination of pregnancy in selected cases [6].

In order to have the opportunity to choose any option it is of primary importance to establish the diagnosis prenatally $[5,7]$. Ultrasonography and MRI are the tools of first choice in this aspect [4-6].

Unfortunately this was not the case in our presented first set of conjoined twins: prenatal ultrasonography was never done, and the traumatic delivery in a regional hospital possibly caused the rupture of the amniotic membrane of the omphalocele, exposure of the shared liver and evisceration of the bowel.

All these circumstances, together with delayed transfer to the NICU in our institution, resulted in the necessity of emergency separation without detailed diagnosis and preoperative preparation. It turned out that the separation of these conjoined twins was indeed technically feasible and even twin B (with atretic biliary ducts) could have had a chance of survival, as well as twin A.

It is quite a different story as far as our $2^{\text {nd }}$ set of conjoined twins is concerned. They were born in our institution 12 years later with full prenatal diagnosis established at 26 weeks of gestation. As the anatomy of the fusion and shared organs was exactly known well in advance and the general condition of the twins was quite satisfactory all the time, the separation could be performed as an elective procedure at the chosen, optimal moment, and the age of 3 months seemed to be the proper time. The separation went smoothly and postoperative progress was also uneventful. Now both girls are more than 2 years old and are doing very well.

In conclusion, the feasibility of separation of conjoined twins depends mostly on the anatomy of the anomaly. The variety of features is enormous and so is the prognosis: from rather optimistic to lethal. One thing can be stated for sure: the more and the earlier one knows, the more likely one is to succeed against the odds.

\section{References}

1. Spitz L. Conjoined twins. Prenat Diagn 2005; 25: 814-9.

2. Spitz L, Kiely EM. Experience in the management of conjoined twins. Br J Surg 2002; 89: 1188-92.

3. Al Rabeeah A. Conjoined twins-past, present, and future. J Pediatr Surg 2006; 41: 1000-4.

4. Basgul A, Kavak ZN, Sezen D, et al. Thoraco-omphalopagus conjoined twins detected as early as 9 weeks of gestation. Fetal Diagn Ther 2006; 21: 477-80.

5. Martinez L, Fernandez J, Pastor I, et al. The contribution of modern imaging to planning separation strategies in conjoined twins. Eur J Pediatr Surg 2003; 13: 120-4.

6. Winker N, Kennedy A, Byrne J, et al. The imaging spectrum of conjoined twins. Ultrasound Q 2008; 24: 249-55.

7. Mackenzie TC, Crombleholme TM, Johnson MP, et al. The natural history of prenatally diagnosed conjoined twins. J Pediatr Surg 2002; 37: 303-9. 